\title{
Barriers and Opportunities for
} Actionable Knowledge Production in Drought Risk Management: Embracing the Frontiers of Co-production

OPEN ACCESS

Edited by:

lan Holman,

Cranfield University, United Kingdom

Reviewed by:

Andrea Grant,

New Zealand Forest Research Institute Limited (Scion), New Zealand Erik W. Johnston, Arizona State University, United States

${ }^{*}$ Correspondence: Sam Grainger sam.grainger@mu.ie

Specialty section: This article was submitted to Interdisciplinary Climate Studies, a section of the journal Frontiers in Environmental Science

Received: 02 September 2020 Accepted: 16 February 2021

Published: 08 April 2021

Citation:

Grainger S, Murphy $C$ and Vicente-Serrano SM (2021) Barriers and Opportunities for Actionable Knowledge Production in Drought Risk Management: Embracing the Frontiers of Co-production.

Front. Environ. Sci. 9:602128. doi: 10.3389/fenvs.2021.602128

\author{
Sam Grainger ${ }^{1 *}$, Conor Murphy ${ }^{1}$ and Sergio M. Vicente-Serrano ${ }^{2}$ \\ ${ }^{1}$ Irish Climate Analysis and Research UnitS (ICARUS), Department of Geography, Maynooth University, Maynooth, Ireland, \\ ${ }^{2}$ Instituto Pirenaico de Ecologia, Consejo Superior de Investigaciones Cientificas (IPE-CSIC), Zaragoza, Spain
}

Drought risks pose serious threats to socio-ecological systems, built environments, livelihoods and human wellbeing. Managing these risks requires long-term collaboration between diverse groups with different values, interests and forms of knowledge. Funders, researchers and practitioners have increasingly advocated for collaborative models of knowledge production in which all participants recognise the multiple ways of understanding drought risk and strive to co-create knowledge for decision making. Such transdisciplinary research approaches aim to develop and sustain more equitable and meaningful interactions between scientific and societal actors, and have been shown to increase knowledge use and build resilience to climate variability. In practice, however, collaborations around drought remain largely science-driven and, as a result, can struggle to produce actionable knowledge necessary to better manage drought risk. This article draws from drought studies and related transdisciplinary fields to highlight common barriers inhibiting actionable knowledge production across a broad range of drought risk management contexts. We also propose opportunities for improved knowledge production that can guide researchers, practitioners and funders seeking to engage in transdisciplinary work. Diverse understandings of drought risk have hindered widespread advances in knowledge production and resilience building. We argue for multidisciplinary researchers to come together with stakeholders and focus on creating inclusive and context-driven environments. While not appropriate or cost-effective in all situations, co-production between researchers, practitioners and other stakeholder groups offers opportunities for actionable management plans and policies that reflect the complex and contested problem framings and socio-ecological contexts in which droughts impact society.

Keywords: co-production, actionable knowledge, drought risk management, drought impacts, transdisciplinarity 


\section{RECENT PROGRESS IN KNOWLEDGE PRODUCTION FOR DROUGHT RISK MANAGEMENT}

Droughts are the result of complex interactions between physical, biological and social systems (Wilhite and Pulwarty, 2017). In this human-dominated era, prolonged droughts pose serious threats to economies, societies and the environment (Wilhite, 2012; Van Loon et al., 2016a). Their impacts are difficult to observe and quantify as they affect sectors in myriad ways (Van Loon et al., 2016b; Vicente-Serrano et al., 2020). Drought risks are a function of both the probability and severity of events (exposure) and underlying vulnerability of the exposed system, community or society (Vogt et al., 2018). Prolonged dry conditions can increase the risk of wildfires and water shortages which can have adverse effects on ecology, water supplies, public services, infrastructure, agriculture and industry. At an individual level, these impacts can affect people's recreational activities, livelihoods and ultimately their well-being. Historically, droughts have traditionally been managed using reactive, crisis-driven approaches (see Pulwarty and Sivakumar, 2014). In recent decades, numerous studies have argued for proactive approaches to managing drought risk based on long-term monitoring and multi-actor engagement (see Wilhite et al., 2014; Bachmair et al., 2016a; Finnessey et al., 2016).

Understanding where, when and how drought conditions evolve can give those affected time to prepare and act to minimise harm. In recent decades, there have been significant advances in drought monitoring and early warning, seasonal forecasting and data processing (Wilhite and Pulwarty, 2017; Hannaford et al., 2018). Monitoring and early warning systems (MEWS) have been developed to continuously track and, in some cases, forecast hydrometeorological variables at different scales (Wilhite, 2006; Hannaford et al., 2018). There have also been considerable efforts in repackaging these data in the form of drought indicators or indices (e.g., Hao and Singh, 2015). Several studies have assessed the links between different drought indicators (e.g., Vicente-Serrano and López-Moreno, 2005; Vicente-Serrano et al., 2012), and drought impacts in different sectors (Bachmair et al., 2016b).

However, while data-driven MEWS can characterise environmental conditions, they have limitations when it comes to connecting with how drought is locally experienced and recorded by impacted sectors and communities (Bachmair et al., 2016a; Ferguson et al., 2016). For example, drought is often scientifically defined, based on standardised indices that have little meaning for those impacted. Consequently, MEWS can struggle to produce actionable knowledge necessary to reduce vulnerability and enhance long-term resilience (Kirchhoff et al., 2013). There remains a simplistic belief in some literature (see e.g., Finnessey et al., 2016) that producing and simply communicating scientific information can depoliticise complex and highly contested societal problems such as climate change, loss of biodiversity and drought. In reality, such top-down approaches can reinforce existing unequal relationships (Murphy et al., 2016) and the perception that science alone can produce and deliver the knowledge needed to address complex social problems (Pohl et al., 2010; Turnhout et al.,
2020). For example, creating narrow definitions of drought that suit empirical scientists from meteorology, hydrology, engineering, economics or agricultural science automatically marginalises less technical sectors and types of knowledge. In response, a growing body of literature has emerged (see Cash and Borck, 2006; Kirchhoff et al., 2013; Lemos et al., 2018a), advocating instead for transdisciplinary research that seeks to create meaningful knowledge for decision makers, communities and organisations through inclusive and interactive approaches (see Norström et al., 2020).

Transdisciplinarity can be defined as a commitment by academics and non-academics to integrate multiple forms of knowledge and perspectives within a collaborative research process (Suldovsky et al., 2018). There is growing evidence, particularly in the context of addressing complex socioecological challenges, that transdisciplinary approaches (e.g., knowledge co-production, post-normal science, action research) increase the likelihood of producing actionable knowledge (i.e., knowledge that is perceived as sufficiently credible, salient and legitimate to be used in decision making) (Cash et al., 2003; Lemos et al., 2018b). As a result, funders, researchers and practitioners are turning to more collaborative models of knowledge production and management to build resilience to intractable climate-related hazards such as drought.

While drought literature on transdisciplinary knowledge production is limited, recent drought studies draw from social sciences to argue for improved understanding of transdisciplinary knowledge-making practices and for stakeholders to play a more prominent role in the development of open and transparent MEWS (Van Loon et al., 2016b; Hannaford et al., 2018). For example, while exploring drought impacts and MEWS development in Europe, North America, and Australia, the "DrIVER" project incorporated learnings from stakeholder workshops to develop collective insights into different perspectives of drought impacts and MEWS needs (Collins et al., 2016; Hannaford et al., 2018). In a Mediterranean context, Turco et al. (2019) developed a fire forecasting system that merged user relevant information with seasonal climate forecasts to provide tailored outlooks for fire managers in Catalunya. Ferguson et al. (2016) collaborated with a Native American community in the United States Southwest on a drought information system that combined local observations and knowledge with scientific monitoring data. Experiences in sub-Saharan Africa have also shown that ignoring the cultural and power dynamics of different ways of knowing (traditional and scientific knowledge) can reinforce tensions within communities and enhance vulnerability to drought (Murphy et al., 2016). Such endeavours are pioneering integration of scientific tools and data with local understandings of drought impacts, towards shared or "co-produced" definitions of drought. With drought research taking this turn and attempting to operate in a transdisciplinary space, it is important to reflect on some inherent challenges of knowledge production for drought risk management and how they can potentially be addressed.

In this focused review, we draw on drought specific and related literature from more mature transdisciplinary fields that share similar epistemic foundations and risk-based decision-making 
TABLE 1 | Barriers to and opportunities for actionable knowledge production in drought risk management.

\section{Barriers}

Droughts have different meanings

Droughts can be perceptually challenging

Droughts are context specific

Droughts are difficult to predict

\section{Opportunities}

Deliberately co-produce

Understand stakeholder context and needs

Explicitly recognise diverse drought meanings

Create enabling environments and be transparent about uncertainties contexts (e.g., water governance, climate services, climate risk management and sustainability science). We also draw upon our own insights and practical experiences collaborating with societal actors on climate risk, drought and water resources decision making. Our objectives are to 1) identify common barriers to the production of actionable knowledge and 2) propose opportunities for improved knowledge production that can guide researchers, practitioners and funders seeking to engage in transdisciplinary drought work across diverse drought contexts and scales (Table 1). We conclude by elaborating some of the benefits and potential pitfalls of co-production, discussing the important role of social science in drought research, and recommending some future research directions.

\section{BARRIERS TO ACTIONABLE KNOWLEDGE PRODUCTION FOR DROUGHT RISK MANAGEMENT}

Drought affects different parts of the hydrological cycle, environment and society in ways that are highly subjective, pervasive and difficult to quantify (Bachmair et al., 2016a). The complexity of drought as a hazard, and contestation over how drought impacts society prevents more nuanced understandings of drought and knowledge exchange (Wilhite and Glantz, 1985; Redmond, 2002; Kallis, 2008; Ferguson et al., 2016). This section identifies some of the fundamental barriers inhibiting actionable knowledge production for drought risk management.

\section{Droughts Have Different Meanings}

At their most abstract, droughts are periods characterised by adverse effects from insufficient water. Drought impacts are often framed from an agricultural, economic or ecological perspective. Farmers may associate reduced yield or loss of harvest or livestock with dry conditions; economists may only consider conditions to be drought-like when demand for water exceeds supply; ecologists may focus on the impact of dry conditions on ecological health and water quality (Wilhite and Glantz, 1985; Mishra and Singh, 2010). Drought can also be defined in operational terms based on agreed criteria that help planners decide when to declare an event and activate response plans (Estrela and Vargas, 2012; Bachmair et al., 2016a; Maia and Vicente-Serrano, 2017). However, there can be no universal definition that relates to how droughts impact social systems (Lloyd-Hughes, 2014; Kohl and Knox, 2016). Drought and its impacts mean different things to different people depending on their specific interests, experiences and context. Moreover, thresholds and descriptions of event severity (moderate vs. severe) often differ depending on how drought impacts are framed by dominant voices, emphasising the importance of facilitating integrative assessments and perspectives that draw on diverse experiences. How we define drought can draw out preconditioned biases and a priori alienate or empower different stakeholders, indicating which impacts, sectors and types of knowledge have greater legitimacy in a policy or decisionmaking process.

\section{Droughts Can Be Perceptually Challenging}

Droughts are typically associated with drier than normal weather (meteorological drought). Reductions in precipitation can drive soil moisture deficits (agricultural drought) and in time lower surface and sub-surface water levels in a catchment (hydrological drought). However, drought evolution depends on the magnitude, timing and duration of the precipitation anomaly, the type of soil and land cover, dominant runoff pathways, geology and increasingly engineering and management interventions.

Drought impacts can propagate slowly without being immediately seen or experienced (Wilhite, 2012). As a result, impacts on public services, businesses and communities may also not immediately be attributed to drought conditions. Purely conceptual or scientific characterisations of drought have limited relevance for many stakeholders, particularly when the spatial and temporal resolution of the information provided does not match with their context (Ferguson et al., 2016). Drought planning is a particular challenge where recent societal and institutional experiences of drought may not be reflective of actual risk due to long-term climate variability (Murphy et al., 2017). Rivers or reservoirs in a region may appear to be at normal levels due to careful management, but low soil moisture may be impacting rain-fed agricultural production. In fact, hydrological droughts can persist even after heavy rainfall or flooding.

\section{Droughts Are Context Specific}

A particular socio-ecological and historical context will influence drought risk perception (Gil et al., 2000). Seven days without rainfall might be considered a meteorological drought in traditional agricultural societies that rely on precipitation on almost a daily basis during the rainy season. However, in desert societies where rainfall is scarce, such occurrences would be unremarkable.

How people perceive and respond to drought is strongly related to past experiences and memories (Taylor et al., 1988). Throughout history, drought-prone societies have developed culturally embedded rules of thumb or heuristics derived from 
experiential knowledge and mental models of their local environment (Courkamp et al., 2019). In some places, increases in extreme climate events are likely to have an effect on risk perception and on how people and societies understand seasons and climate variability in the future. Recent attention has been drawn to "flash drought" events in humid regions, characterised by their sudden onset, rapid intensification and severe impacts (Pendergrass et al., 2020).

At a societal level, droughts may be downgraded or "forgotten" entirely if they occur around the same time as a heat wave or prior to a significant flood event (Ciais et al., 2005; Marsh et al., 2013; Shepherd et al., 2018). It can be difficult to communicate drought risk in cultures with a perennially wet climate, associated with green landscapes (Weitkamp et al., 2019). In northern European countries, droughts are usually associated with hot weather which, in turn, evokes positive memories of being outdoors and enjoying the sunshine (Bruine de Bruin et al., 2016). As a result, droughts are not always seen as major hazards that require long-term planning. Perceptions of drought risk can also change as a function of socio-economic conditions and dynamic policy landscapes (Gil et al., 2000). For example, in the mid 20th century, Spanish society moved from a focus on meteorological droughts to hydrological droughts as their economy became less reliant on rainfed agriculture.

\section{Droughts are Difficult to Predict}

It is difficult to develop confident meteorological forecasts of drought more than two weeks in advance. With the exception of some tropical and subtropical regions in which climate variability is strongly determined by sea surface temperature variability (Vicente-Serrano et al., 2011), in the majority of the world regions the skill of seasonal forecasting is still very low to be effective in developing accurate seasonal drought forecasts (Bechtold et al., 2008; Dutra et al., 2013). Such capacity would be very useful to anticipate possible impacts and to allow preparedness of economic sectors to associated losses, hydrological managers to improve dam operation and optimization of available water resources and environmental managers to prepare for possible hazards (e.g., fire risk) and to reduce soil erosion and land degradation (e.g., with management of livestock grazing). While recent studies have suggested some improvement in skill (e.g., Davini and D'Andrea, 2020; Smith et al., 2020), current drought forecasting systems (e.g., https:// www.drought.gov/drought/data-maps-tools/outlooks-forecasts) are still subject to large uncertainties.

\section{OPPORTUNITIES FOR ACTIONABLE KNOWLEDGE PRODUCTION FOR DROUGHT RISK MANAGEMENT}

There are a number of opportunities for researchers, practitioners and funders seeking to overcome these barriers. These are neither comprehensive nor prescriptive but offer insights from drought and related literature that can inform a pragmatic approach to producing actionable knowledge in a range of drought-sensitive decision-making contexts.

\section{Focus on Co-Producing Rather Than Translating Knowledge}

Public-facing drought information systems tend to focus on translating scientific knowledge for a wide range of stakeholders (Hannaford et al., 2018). Integration of scientific and non-scientific knowledge remains rare (Giordano et al., 2013; Solano-Hernandez et al., 2020), with some exceptions (e.g., Estrela and Vargas, 2012). This centralised, technocratic model of knowledge production is ineffective because it creates a disconnect between monitoring networks, scientists and sector-specific drought planning (Hannaford et al., 2018).

Collaborative knowledge production (commonly referred to as "co-production") can be defined in normative terms, as a learning process that deliberately brings together diverse perspectives to co-create actionable knowledge and new practices (Bremer and Meisch 2017; Lemos et al., 2018b). Co-production should be interactive, iterative, context-driven, problem-focused and involve deep engagement with non-scientific knowledge systems (Norström et al., 2020). Co-produced knowledge is more likely to be perceived as credible, salient and legitimate (Cash et al., 2003). While systematic assessments are rare (Mach et al., 2019; Arnott et al., 2020; Jagannathan et al., 2020), coproduction has been shown to increase the likelihood of knowledge use in decision-making (Lemos et al., 2018b).

However, assembling a sufficiently broad group of actors, while keeping the process practically and strategically manageable requires considerable time, resources and expertise (Page and Dilling, 2019; Norström et al., 2020). Potential participants may not have sufficient capacity or motivation to engage in co-productive processes (Page and Dilling, 2019). Many academics are still primarily incentivised to conduct disciplinary science that cannot directly address societal challenges (Dilling and Lemos 2011). Conversely, practitioners and other stakeholders may work within professional contexts that do not reward iterative learning, innovation and critical reflection (Norström et al., 2020).

Successful co-production is predicated on including a plurality of perspectives, which often requires the disruption of established roles and routines (Vincent et al., 2018; Turnhout et al., 2020). Deep rooted power imbalances can prevent engagement, reproduce knowledge hierarchies and, consequently, undermine the co-production process (Mobjörk, 2010; Reed et al., 2014; Brandt et al., 2018). To avoid such pitfalls, it is important that all actors involved in the co-productive processes are committed to achieving a common goal and able to regularly and systematically reflect on and discuss the extent to which their understandings and values are being represented (Reed et al., 2014; Norström et al., 2020).

\section{Iteratively Analyse Stakeholder Needs and Context}

Given the complex and multi-sectoral nature of drought it is vital that a thorough analysis of potential stakeholders and their decisionmaking contexts is conducted prior to and throughout collaborations. Top-down, "loading dock" approaches that focus solely on information provision often fail to consider the complexity 
and dynamism of local cultural sensitivities around the legitimacy of different types of knowledge systems (Cash and Borck, 2006). This can create friction between local stakeholders and ultimately result in mal-adaptative decision making (Murphy et al., 2016). Uncritical mapping and selection of potential stakeholders (e.g., just targeting water managers) can reinforce existing narrow perceptions and power structures. It is important to know whether stakeholders are already used to dealing with hydrological variability or other climate-related hazards such as flooding. Businesses may also have to prioritise other stressors/threats above drought preparedness (e.g., the COVID-19 pandemic) when making decisions.

Contextual analysis and participatory design approaches can inform the development of tailored communications and interactions (Hannaford et al., 2018; Grainger et al., 2020). Some stakeholders may require technical information (SPI, severities, probabilities), others might just want high-level information about the general hydrological trend. An appraisal of the 2009 United Kingdom Climate Projections (UKCP09) highlighted that scientists often assume that users will be highly numerate and able to handle technical information (Porter and Dessai, 2017). This often leads to parachuting default or familiar approaches when interacting with stakeholders. Our experiences would suggest that, despite the inclusion of stakeholder analysis and engagement within some drought projects, researchers from the social and behavioral sciences are rarely involved in framing, planning and designing these interactions. Funders and natural scientists should acknowledge how valuable their contribution could be to knowledge production and reach out to these disciplines as early as possible in the project creation process.

\section{Explicitly Recognise Diverse Understandings of Drought}

It is crucial to recognise that plurality of perspectives make drought an inherently complex and context-differentiated hazard (Collins and Ison, 2009; Lange et al., 2017; Hannaford et al., 2018). As a result, no single perspective can presume superiority over another, and claim to have a definitive understanding of drought and potential solutions. The inclusion of multiple forms of knowledge has the potential to enhance knowledge use and build trust between researchers and drought-sensitive sectors.

Any characterisation of drought that strives for societal relevance must consider what makes drought socially relevant in that particular context (Ferguson et al., 2016). We would therefore encourage researchers to support drought sensitive decision makers to develop their own drought definition tailored to their own context. This can be achieved through collaborative ground-truthing of drought indicators with stakeholder knowledge (Bachmair et al., 2016a) and with an understanding of their specific needs (Estrela and Vargas, 2012).

\section{Create Enabling Institutional Environments}

Effective knowledge production requires collaboration between different sectors and knowledge systems operating at various spatial and temporal scales. Currently, links between community, national and global-scale drought management are weak (Pulwarty and Sivakumar, 2014). This fragmented management context is exacerbated by science and institutional systems that are grounded in top-down modes of knowledge production and mobilization. Drought researchers and planners might benefit from working through organisations operating at the interface between science and policy [known as boundary organisations (Guston, 2001)] to help connect different sectoral drought plans and knowledge systems (e.g., water supply and agricultural sector) (Hannaford et al., 2018). Page and Dilling (2019) suggest taking advantage of existing intra-sectoral communities of practices or local "champions" that may be influential within broader stakeholder groups (e.g., water managers/farmers).

The use of climate information and related services within drought risk management has been promoted by several key international initiatives including the United Nations' Global Framework for Climate Services and Integrated Drought Management Programme (Finnessey et al., 2016). However, Turnhout et al. (2020) show that these types of science-led initiatives are often dominated by depoliticisation dynamics that reinforce rather than mitigate existing uneven postcolonial politics. It is, therefore, vital that the drought research community reflect upon important institutional questions around who should instigate and drive collaborations (Hannaford et al., 2018).

\section{Openly Discuss and Characterise Uncertainty}

Drought management is beset by scientific and socio-economic uncertainties that require joint knowledge and problem solving by researchers, practitioners and other societal actors. Decision makers should have awareness of the uncertainty associated with different forms of knowledge and knowledge production processes (Fischhoff and Davis, 2014). However, this can be problematic, particularly when dealing with inherently uncertain processes in risk averse cultural contexts driven by institutional expectations for precision and accuracy (Taylor et al., 2021). Overlooking uncertainty in response to these expectations may result in a false sense of certainty, potentially leading to mal-adaptive decision making and loss of trust in scientific partners (Macintosh, 2013; LeClerc and Joslyn, 2015). It is therefore important to manage expectations carefully, and characterise uncertainties in a manner that is transparent, relevant and understandable to all stakeholders. When engaging with broader and non-scientific audiences, storylines or narrative approaches can help connect with people's innate understanding of future uncertainty and reveal important points of commonality (Shepherd et al., 2018; Jack et al., 2020).

\section{CONCLUSION}

Despite decades observing and quantifying changes in hydrological extremes, drought remains intractable in clear scientific terms and as a risk for societies to manage. Recent drought research has taken the first steps towards connecting 
with, and making actionable knowledge for, those communities and sectors impacted by drought impacts. In this focused review, we have reflected on this progress by highlighting some key barriers to knowledge production and proposing potential opportunities for strengthening drought knowledge.

Drought perceptions are strongly differentiated among scientific disciplines, stakeholders and economic sectors, and are subject to change as a function of hazard severity, socioeconomic and environmental conditions. Context is crucial, with drought having very different meanings and experiences in time and space-from humid and semi-arid regions to local differences within the same catchment. These scientific, perceptual and contextual challenges have made it difficult to engage with different sectors on anything other than a reactive basis (Wilhite, 2012).

To overcome these barriers, we urge those involved in drought risk management to embrace co-production as a model of engagement and knowledge production. This will require that researchers become partners in knowledge creation rather than solely producers of knowledge and to recognise multiple ways of understanding drought risk. In the right collaborative environment, explicit interaction with different knowledge systems can help to build trust, develop shared understandings and enrich knowledge outcomes (Tobias et al., 2019). Creating an enabling environment that accommodates a diverse understanding of drought is far from straightforward, requiring skills not typically required in natural science.

As we have stated earlier, drought literature on co-production is limited. Further exploration of the challenges raised in this article require future research into current knowledge production practices and use in specific drought risk management contexts to better understand the implications of "silo-ed" knowledge on decision making. The social sciences and humanities need to play a more prominent role in co-produced drought research not only as facilitators but also as action researchers so that we can better understand the cultural, political and institutional dimensions that influence drought understandings and risk management processes.

We should expect individual, disciplinary and organisational resistance to new ways of working as power dynamics and knowledge hierarchies are slowly revealed and dismantled. There are inevitable trade-offs between the time and resources required to co-produce research and the expectation on researchers to publish and advance in their careers.

\section{REFERENCES}

Arnott, J. C., Kirchhoff, C. J., Meyer, R. M., Meadow, A. M., and Bednarek, A. T. (2020). Sponsoring actionable science: what public science funders can do to advance sustainability and the social contract for science. Curr. Opin. Environ. Sustain. 42, 38-44. doi:10.1016/j.cosust.2020.01.006

Bachmair, S., Stahl, K., Collins, K., Hannaford, J., Acreman, M., Svoboda, M., et al. (2016a). Drought indicators revisited: the need for a wider consideration of environment and society. WIREs Water 3 (4), 516-536. doi:10.1002/wat2.1154

Bachmair, S., Svensson, C., Hannaford, J., Barker, L. J., and Stahl, K. (2016b). A quantitative analysis to objectively appraise drought indicators and model
Transdisciplinary research will not be appropriate in all drought contexts and all parties will need to carefully consider whether the costs outweigh the expected benefits. Success criteria for co-production will differ greatly and evaluations will need to reflect the complexity of stakeholder expectations, motivation and capacities (Wall et al., 2017; Bremer et al., 2021). Funders, researchers and practitioners have unique ways of assessing whether to use a co-production approach and collaborators need to explicitly acknowledge differences in motivations early in the process. However, a common goal running through transdisciplinary research should be the emergence of a shared purpose and learning in groups (or social learning), both collectively and individually. Proactive approaches to monitoring and evaluation, adaptive project programming and participant flexibility are also critical within co-production processes (Vincent et al., 2018). While collaborative efforts may not immediately provide solutions, mutual exchange of experiences, ideas and values can, in the long-term, facilitate collective action and develop the vital capacities, networks and social capital needed to manage drought risk.

\section{AUTHOR CONTRIBUTIONS}

SG: Article conception and design, drafting of manuscript; CM: Article conception and design, critical revision; SV-S: Critical revision.

\section{FUNDING}

Support received from the EPA and the Irish Government and JPI-climate Project number is CROSSDRO (2019-CCRPMS.60).

\section{ACKNOWLEDGMENTS}

This work was undertaken as part of CROSSDRO (2019-CCRPMS.60) a European project financed by the AXIS (Assessment of Cross $(\mathrm{X})$-sectoral climate Impacts and pathways for Sustainable transformation) JPI-Climate co-funded call of the European Commission with funding from the Irish Environmental Protection Agency and the Government of Ireland. drought impacts. Hydrol. Earth Syst. Sci. 20 (7), 2589-2609. doi:10.5194/ hess-20-2589-2016

Bechtold, P., Köhler, M., Jung, T., Doblas-Reyes, F., Leutbecher, M., Rodwell, M. J., et al. (2008). Advances in simulating atmospheric variability with the ECMWF model: from synoptic to decadal time-scales. Q. J. R. Meteorol. Soc. J. Atmos. Sci. Appl. Meteorol. Phys. Oceanogr. 134 (634), 1337-1351. doi:10.1002/qj.289

Brandt, F., Josefsson, J., and Spierenburg, M. (2018). Power and politics in stakeholder engagement: farm dweller (in)visibility and conversions to game farming in South Africa. Ecol. Soc. 23, 32. doi:10.5751/es-10265-230332

Bremer, S., and Meisch, S. (2017). Co-production in climate change research: reviewing different perspectives. Wiley Interdiscip. Rev. Clim. Change 8 (6), 1-22. doi: $10.1002 /$ wcc. 482 
Bremer S., Wardekker A., Jensen E. S., and van der Sluijs J. P. (2021). Quality assessment in co-developing climate services in Norway and the Netherlands. Front. Clim. 3, 627665. doi:10.3389/fclim.2021.627665

Bruine de Bruin, W., Lefevre, C. E., Taylor, A. L., Dessai, S., Fischhoff, B., and Kovats, S. (2016). Promoting protection against a threat that evokes positive affect: the case of heat waves in the United Kingdom. J. Exp. Psychol. Appl. 22 (3), 261-271. doi:10.1037/xap0000083

Cash, D. W., Clark, W. C., Alcock, F., Dickson, N. M., Eckley, N., Guston, D. H., et al. (2003). Knowledge systems for sustainable development. Proc. Natl. Acad. Sci. U.S.A. 100, 8086. doi:10.1073/pnas. 1231332100

Cash, D. W., Borck, J. C., and Patt, A. G. (2006). Countering the loading-dock approach to linking science and decision making. Sci. Technol. Hum. Values 31 (4), 465-494. doi:10.1177/0162243906287547

Ciais, P., Reichstein, M., Viovy, N., Granier, A., Ogée, J., Allard, V., et al. (2005). Europe-wide reduction in primary productivity caused by the heat and drought in 2003. Nature 437 (7058), 529-533. doi:10.1038/nature03972

Collins, K., Hannaford, J., Svoboda, M., Knutson, C., Wall, N., Bernadt, T., et al. (2016). Stakeholder coinquiries on drought impacts, monitoring, and early warning systems. Bull. Am. Meteorol. Soc. 97 (11), ES217-ES220. doi:10.1175/ bams-d-16-0185.1

Collins, K., and Ison, R. (2009). Jumping off Arnstein's ladder: social learning as a new policy paradigm for climate change adaptation. Environ. Policy Gov. 19 (6), 358-373. doi:10.1002/eet.523

Courkamp, J. S., Knapp, C. N., and Allen, B. (2019). Immersive Co-production to inform ranch management in gunnison, Colorado, USA. Rangelands 41 (4), 178-184. doi:10.1016/j.rala.2019.05.002

Davini, P., and D'Andrea, F. (2020). From CMIP-3 to CMIP-6: northern Hemisphere atmospheric blocking simulation in present and future climate. J. Clim. 23, 10021-10038. doi:10.1175/JCLI-D-19-0862.1

Dilling, L., and Lemos, M. C. (2011). Creating usable science: opportunities and constraints for climate knowledge use and their implications for science policy. Glob. Environ. Change 21 (2), 680-689. doi:10.1016/j.gloenvcha.2010.11.006

Dutra, E., Magnusson, L., Wetterhall, F., Cloke, H. L., Balsamo, G., Boussetta, S., et al. (2013). The 2010-2011 drought in the Horn of Africa in ECMWF reanalysis and seasonal forecast products. Int. J. Climatol. 33 (7), 1720-1729. doi:10.1002/joc.3545

Estrela, T., and Vargas, E. (2012). Drought management plans in the European Union. The case of Spain. Water resour. Manag. 26, 1537-1553. doi:10.1007/ s11269-011-9971-2

Ferguson, D. B., Masayesva, A., Meadow, A. M., and Crimmins, M. A. (2016). Rain gauges to range conditions: collaborative development of a drought information system to support local decision-making. Weather Clim. Soc. 8 (4), 345-359. doi:10.1175/wcas-d-15-0060.1

Finnessey, T., Hayes, M., Lukas, J., and Svoboda, M. (2016). Using climate information for drought planning. Clim. Res. 70 (2-3), 251-263. doi:10. $3354 / \mathrm{cr} 01406$

Fischhoff, B., and Davis, A. L. (2014). Communicating scientific uncertainty. Proc. Natl. Acad. Sci. U. S. A. 111 (Suppl 4), 13664-13671. doi:10.1073/pnas. 1317504111

Gil, A. M., Cantos, J. O., and Amorós, A. M. R. (2000). Diferentes percepciones de la sequía en España: adaptación, catastrofismo e intentos de corrección. Investig. Geogr. (23), 5-46. doi:10.14198/ingeo2000.23.06

Giordano, R., Preziosi, E., and Romano, E. (2013). Integration of local and scientific knowledge to support drought impact monitoring: some hints from an Italian case study. Nat. Hazards 69 (1), 523-544. doi:10.1007/s11069-013-0724-9

Grainger, S., Ochoa-Tocachi, B. F., Antiporta, J., Dewulf, A., and Buytaert, W. (2020). Tailoring infographics on water resources through iterative, usercentered design: a case study in the Peruvian andes. Water Resour. Res. 56 (2), 1-16. doi:10.1029/2019wr026694

Guston, D. H. (2001). Boundary organizations in environmental policy and science: an introduction. Sci. Technol. Hum. Values 26, 399-408. doi:10. $1177 / 016224390102600401$

Hannaford, J., Collins, K., Haines, S., and Barker, L. J. (2018). Enhancing drought monitoring and early warning for the United Kingdom through stakeholder coinquiries. Weather Clim. Soc. 11 (1), 49-63. doi:10.1175/wcas-d-18-0042.1

Hao Z., and Singh, V. P. (2015). Drought characterization from a multivariate perspective: a review. J. Hydrol. 527, 668-678. doi:10.1016/j.jhydrol.2015.05.031
Jack, C. D., Jones, R., Burgin, L., and Daron, J. (2020). Climate risk narratives: an iterative reflective process for co-producing and integrating climate knowledge. Clim. Risk Manag. 29, 100239. doi:10.1016/j.crm.2020.100239

Jagannathan, K., Arnott, J. C., Wyborn, C., Klenk, N., Mach, K. J., Moss, R. H., et al. (2020). Great expectations? reconciling the aspiration, outcome, and possibility of co-production. Curr. Opin. Environ. Sustain. 42, 22-29. doi:10.1016/j.cosust. 2019.11.010

Kallis, G. (2008). Droughts. Annu. Rev. Environ. Resour. 33, 85-118. doi:10.1146/ annurev.environ.33.081307.123117

Kirchhoff, C. J., Carmen Lemos, M., and Dessai, S. (2013). Actionable knowledge for environmental decision making: broadening the usability of climate science. Annu. Rev. Environ. Resour. 38 (1), 393-414. doi:10.1146/annurev-environ022112-112828

Kohl, E., and Knox, J. A. (2016). My drought is different from your drought: a case study of the policy implications of multiple ways of knowing drought. Weather Clim. Soc. 8 (4), 373-388. doi:10.1175/wcas-d-15-0062.1

Lange B., Holman I., and Bloomfield J. P. (2017). A framework for a joint hydrometeorological-social analysis of drought. Sci. Total Environ. 578, 297-306. doi:10.1016/j.scitotenv.2016.10.145

LeClerc, J., and Joslyn, S. (2015). The cry wolf effect and weather-related decision making. Risk Anal. 35, 385-395. doi:10.1111/risa.12336

Lemos, M. C., Eakin, H., Dilling, L., and Worl, J. (2018a). Social sciences, weather, and climate change. Meteorol. Monogr. 59, 26-31. doi:10.1175/ amsmonographs-d-18-0011.1

Lemos, M. C., Arnott, J. C., Ardoin, N. M., Baja, K., Bednarek, A. T., Dewulf, A., et al. (2018b). To co-produce or not to co-produce. Nat. Sustain. 1 (12), 722-724. doi:10.1038/s41893-018-0191-0

Lloyd-Hughes, B. (2014). The impracticality of a universal drought definition. Theor. Appl. Climatol. 117 (3-4), 607-611. doi:10.1007/s00704-013-1025-7

Mach, K. J., Lemos, M. C., Meadow, A. M., Wyborn, C., Klenk, N., Arnott, J. C., et al. (2019). Actionable knowledge and the art of engagement. Curr. Opin. Environ. Sustain. 46, 1-82. doi:10.1016/j.cosust.2020.01.002

Macintosh, A. (2013). Coastal climate hazards and urban planning: how planning responses can lead to maladaptation. Mitig. Adapt Strateg. Glob. Change 18 (7), 1035-1055. doi:10.1007/s11027-012-9406-2

Maia, R., and Vicente-Serrano, S. M. (2017). "Drought planning and management in the iberian Peninsula," in Drought and water crises: integrating science, management, and policy. Editors D. Wilhite and R. S. Pulwarty (Boca Raton, FL: CRC Press), 481-506.

Marsh, T., Parry, S., Kendon, M., and Hannaford, J. (2013). The 2010-12 drought and subsequent extensive flooding: a remarkable hydrological transformation. Bailrigg, England:NERC/Centre for Ecology \& Hydrology.

Mishra, A. K., and Singh, V. P. (2010). A review of drought concepts. J. Hydrol. 391 (1-2), 202-216. doi:10.1016/j.jhydrol.2010.07.012

Mobjörk, M. (2010). Consulting versus participatory transdisciplinarity: a refined classification of transdisciplinary research. Futures 42 (8), 866-873. doi:10. 1016/j.futures.2010.03.003

Murphy, C., Noone, S., Duffy, C., Broderick, C., Matthews, T., and Wilby, R. L. (2017). Irish droughts in newspaper archives: rediscovering forgotten hazards?. Weather 72 (6), 151-155. doi:10.1002/wea.2904

Murphy, C., Tembo, M., Phiri, A., Yerokun, O., and Grummell, B. (2016). Adapting to climate change in shifting landscapes of belief. Clim. Change 134 (1-2), 101-114. doi:10.1007/s10584-015-1498-8

Norström, A. V., Cvitanovic, C., Löf, M. F., West, S., Wyborn, C., Balvanera, P., et al. (2020). Principles for knowledge co-production in sustainability research. Nat. Sustain. 3 (3), 182-190. doi:10.1038/s41893-019-0448-2

Page, R., and Dilling, L. (2019). The critical role of communities of practice and peer learning in scaling hydroclimatic information adoption. Weather Clim. Soc. 11 (4), 851-862. doi:10.1175/wcas-d-18-0130.1

Pendergrass, A. G., Meehl, G. A., Pulwarty, R., Hobbins, M., Hoell, A., AghaKouchak, A., et al. (2020). Flash droughts present a new challenge for subseasonal-to-seasonal prediction. Nat. Clim. Change 10, 191-199. doi:10. 1038/s41558-020-0709-0

Pohl, C., Rist, S., Zimmermann, A., Fry, P., Gurung, G. S., Schneider, F., et al. (2010). Researchers' roles in knowledge co-production: experience from sustainability research in Kenya, Switzerland, Bolivia and Nepal. Sci. Public Policy 37 (4), 267-281. doi:10.3152/030234210x496628 
Porter, J. J., and Dessai, S. (2017). Mini-me: Why do climate scientists' misunderstand users and their needs?. Environ. Sci. Policy 77 (June), 9-14. doi:10.1016/j.envsci.2017.07.004

Pulwarty, R. S., and Sivakumar, M. V. K. (2014). Information systems in a changing climate: early warnings and drought risk management. Weather Clim. Extremes 3, 14-21. doi:10.1016/j.wace.2014.03.005

Redmond, K. T. (2002). The depiction of drought. Bull. Amer. Meteorol. Soc. 83, 1143. doi:10.1175/1520-0477-83.8.1143

Reed, M. S., Stringer, L. C., Fazey, I., Evely, A. C., and Kruijsen, J. H. J. (2014). Five principles for the practice of knowledge exchange in environmental management. J. Environ. Manag. 146, 337-345. doi:10.1016/j.jenvman.2014. 07.021

Shepherd, T. G., Boyd, E., Calel, R. A., Chapman, S. C., Dessai, S., Dima-West, I. M., et al. (2018). Storylines: an alternative approach to representing uncertainty in physical aspects of climate change. Clim. Change 151, 555-571. doi:10.1007/ s10584-018-2317-9

Smith, D. M., Scaife, A. A., Eade, R., Athanasiadis, P., Bellucci, A., Bethke, I., et al. (2020). North Atlantic climate far more predictable than models imply. Nature 583 (7818), 796-800. doi:10.1038/s41586-020-2525-0

Solano-Hernandez, A., Bruzzone, O., Groot, J., Laborda, L., Martínez, A., Tittonell, P., et al. (2020). Convergence between satellite information and farmers' perception of drought in rangelands of North-West Patagonia, Argentina. Land Use Policy 97 (April), 104726. doi:10.1016/j.landusepol.2020.104726

Suldovsky, B., McGreavy, B., and Lindenfeld, L. (2018). Evaluating epistemic commitments and science communication practice in transdisciplinary research. Sci. Commun. 40 (4), 499-523. doi:10.1177/1075547018786566

Taylor, A. L., Grainger, S., Dessai, S., Siu, Y. L., and Bruno Soares, M. (2021). Communicating uncertainty in climate information for China: recommendations and lessons learned for climate services. J. Meteorol. Res. 35, 77-86. doi:10.1007/s13351-021-0118-y

Taylor, J. G., Stewart, T. R., and Downton, M. (1988). Perceptions of drought in the Ogallala aquifer region. Environ. Behav. 20 (2), 150-175. doi:10.1177/ 0013916588202002

Tobias, S., Ströbele, M. F., and Buser, T. (2019). How transdisciplinary projects influence participants' ways of thinking: a case study on future landscape development. Sustain. Sci. 14, 405-419. doi:10.1007/s11625-018-0532-y

Turco M., Marcos-Matamoros R., Castro X., Canyameras E., and Llasat M. C. (2019). Seasonal prediction of climate-driven fire risk for decision-making and operational applications in a Mediterranean region. Sci. Total Environ. 676, 577-583. doi:10.1016/j.scitotenv.2019.04.296

Turnhout, E., Metze, T., Wyborn, C., Klenk, N., and Louder, E. (2020). The politics of co-production: participation, power, and transformation. Curr. Opin. Environ. Sustain. 42, 15-21. doi:10.1016/j.cosust.2019.11.009

Van Loon, A. F., Gleeson, T., Clark, J., Van Dijk, A. I. J. M., Stahl, K., Hannaford, J., et al. (2016a). Drought in the anthropocene. Nat. Geosci. 9 (2), 89-91. doi:10. 1038/ngeo2646

Van Loon, A. F., Stahl, K., Di Baldassarre, G., Clark, J., Rangecroft, S., Wanders, N., et al. (2016b). Drought in a human-modified world: reframing drought definitions, understanding, and analysis approaches. Hydrol. Earth Syst. Sci. 20 (9), 3631-3650. doi:10.5194/hess-20-3631-2016

Vicente-Serrano, S. M., López-Moreno, J. I., Gimeno, L., Nieto, R., Morán-Tejeda, E., Lorenzo-Lacruz, J., et al. (2011). A multiscalar global evaluation of the impact of ENSO on droughts. J. Geophys. Res. Atmos. 116 (D20), D20109. doi:10.1029/2011JD016039

Vicente-Serrano, S. M., Beguería, S., Lorenzo-Lacruz, J., Camarero, J. J., LópezMoreno, J. I., Azorin-Molina, C., et al. (2012). Performance of drought indices for ecological, agricultural, and hydrological applications. Earth Interact. 16 (10), 1-27. doi:10.1175/2012ei000434.1

Vicente-Serrano, S. M., and López-Moreno, J. I. (2005). Hydrological response to different time scales of climatological drought: an evaluation of the Standardized Precipitation Index in a mountainous Mediterranean basin. Hydrol. Earth Syst. Sci. 9 (5), 523-533. doi:10.5194/hess-9-523-2005

Vicente-Serrano, S. M., Quiring, S. M., Peña-Gallardo, M., Yuan, S., and Domínguez-Castro, F. (2020). A review of environmental droughts: increased risk under global warming?. Earth Sci. Rev. 201, 102953. doi:10. 1016/j.earscirev.2019.102953

Vincent, K., Daly, M., Scannell, C., and Leathes, B. (2018). What can climate services learn from theory and practice of co-production?. Clim. Serv. 12 (December), 48-58. doi:10.1016/j.cliser.2018.11.001

Vogt, J. V., Naumann, G., Masante, D., Spinoni, J., Cammalleri, C., Erian, W., et al. (2018). Drought risk assessment. A conceptual framework. Luxembourg, Europe: Publications Office of the European Union.

Wall T. U., MeadowA. M., and Horganic A. (2017). Developing evaluation indicators to improve the process of coproducing usable climate science. Weath. Clim. Soc. 9 (1), 95-107. doi:10.1175/WCAS-D-16-0008.1

Weitkamp, E., McEwen, L., and Ramirez, P. (2019). Communicating the hidden: toward a framework for drought risk communication in maritime climates. Clim. Change 163, 831-850. doi:10.1007/s10584-020-02906-z

Wilhite, D. A. (2012). Breaking the hydro-illogical cycle: changing the paradigm for drought management. Earth 57 (7), 70-71.

Wilhite, D. A. (2006). Drought monitoring and early warning: concepts, progress and future challenges. Geneva, Switzerland:World Meteorological Organization, 1006.

Wilhite, D. A., and Glantz, M. H. (1985). Understanding: the drought phenomenon: the role of definitions. Water Int. 10 (3), 111-120. doi:10.1080/02508068508686328

Wilhite, D. A., Sivakumar, M. V. K., and Pulwarty, R. (2014). Managing drought risk in a changing climate: the role of national drought policy. Weather Clim. Extremes 3 (March), 4-13. doi:10.1016/j.wace.2014.01.002

Wilhite, D., and Pulwarty, R. S. (2017). "Drought as hazard: understanding the natural and social context" in Drought and water crises: integrating science, management, and policy. Editors D. Wilhite and R. S. Pulwarty (Boca Raton, FL: CRC Press), 3-22.

Conflict of Interest: The authors declare that the research was conducted in the absence of any commercial or financial relationships that could be construed as a potential conflict of interest.

Copyright (c) 2021 Grainger, Murphy and Vicente-Serrano. This is an open-access article distributed under the terms of the Creative Commons Attribution License (CC $B Y$ ). The use, distribution or reproduction in other forums is permitted, provided the original author(s) and the copyright owner(s) are credited and that the original publication in this journal is cited, in accordance with accepted academic practice. No use, distribution or reproduction is permitted which does not comply with these terms. 